\title{
Subject Elements Sequence Number
}

National Cancer Institute

\section{Source}

National Cancer Institute. Subject Elements Sequence Number. NCI Thesaurus. Code C87999.

A number that identifies the ordering relations (in time, space, etc.) in a set of subject elements. 